\title{
Weight Management in Patients with Type 2 Diabetes: a Multidisciplinary Real-world Approach
}

\author{
Osama Hamdy $^{1} \cdot$ Sahar Ashrafzadeh ${ }^{1} \cdot$ Adham Mottalib $^{1}$
}

Published online: 17 July 2018

(C) The Author(s) 2018

\begin{abstract}
Purpose of Review Obesity and type 2 diabetes (T2D) are closely linked metabolic diseases. Most individuals with T2D are overweight or obese, which raises their cardiovascular risk. The etiology of both diseases is multifaceted, thus requiring a multidisciplinary approach to control them. This review describes the most effective multidisciplinary approach to weight management in patients with T2D in real-world clinical practice.

Recent Findings Weight management programs in real-world clinical settings lead to long-term weight loss for up to 5 years. Summary Multidisciplinary approach to manage obesity and T2D through weight reduction is feasible in real-world clinical practice and is recommended as part of the treatment plan for patients with T2D who are overweight or obese. Recent data demonstrates that multidisciplinary approach to weight management in patients with T2D results in long-term weight loss and is associated with improved cardiovascular risk factors.
\end{abstract}

Keywords Type 2 diabetes $\cdot$ Obesity $\cdot$ Weight loss $\cdot$ Nutrition therapy $\cdot$ Behavioral therapy $\cdot$ Bariatric surgery

\section{Introduction}

Obesity and type 2 diabetes (T2D) are metabolic diseases that have reached pandemic proportions [1,2]. The United States Centers for Disease Control and Prevention (CDC) reported that most individuals with T2D are overweight or obese [3]. Furthermore, those afflicted by both T2D and obesity are at greater risk for developing cardiovascular disease [4]. The reasons behind the increased prevalence of obesity and T2D are multifaceted and include genetic, environmental, behavioral, and social elements [5•]. Other epigenetic studies explain the increasing prevalence of $\mathrm{T} 2 \mathrm{D}$ from one generation to the next [6].

Controlling both diseases through weight management necessitates an intensive multidisciplinary approach. All clinical guidelines recommend lifestyle modification as the first step in T2D management $[7,8]$. However, primary care physicians

This article is part of the Topical Collection on Obesity

Osama Hamdy

Osama.Hamdy@joslin.harvard.edu

1 Joslin Diabetes Center, Harvard Medical School, One Joslin Place, Boston, MA 02215, USA frequently struggle with lifestyle counseling, which leads to quick initiation of diabetes pharmacotherapy [9-11]. Unfortunately, many of the commonly used antihyperglycemic medications enhance weight gain [12]. As body weight increases, patients become more insulin resistant [13], which further drives the need for higher doses of these medications or adding other antihyperglycemic medications to keep glycemic control at target. This common practice leaves our patients trapped in a vicious cycle.

Conversely, a 7\% reduction in body weight achieved through intensive lifestyle intervention was shown to significantly improve insulin sensitivity [14]. Results from the Diabetes Prevention Program (DPP) demonstrated that weight loss over approximately 3 years helped individuals with prediabetes and obesity reduce the incidence of T2D by $58 \%$ [15]. The Action for Health in Diabetes (Look AHEAD) study reported that lifestyle modification improved glycemic control in addition to lowering body weight among patients with T2D [16]. Although the study did not achieve the primary endpoints of reducing cardiovascular events and mortality, participants in the intensive lifestyle intervention arm of the study had lower medication use for diabetes, hypertension, and dyslipidemia; had fewer hospitalizations; and showed reduced risk for chronic kidney disease and depression in comparison to the control arm of diabetes support and education [16]. We 
recently reported that long-term weight loss can be sustained for 5 years in patients with diabetes and obesity who enrolled in an intensive multidisciplinary lifestyle intervention program in real-world clinical practice [17••].

This review describes the components of a practical and effective multidisciplinary approach to weight management for patients with T2D and obesity in real-world clinical practice.

\section{Multidisciplinary Approach to Weight Management}

Multidisciplinary weight management is recommended by medical societies [18]. Data from the National Weight Control Registry show that narrow approaches to weight reduction are rarely effective but that a broader, multifaceted approach is more sustainable [19, 20]. Furthermore, recent studies showed that multidisciplinary weight management results in long-term maintenance of weight loss [17••, 21].

The Weight Achievement and Intensive Treatment Program (Why WAIT) of the Joslin Diabetes Center is emerging as a viable model of effective multidisciplinary intervention for weight management in real-world clinical practice [22]. The program, which started in 2005, is divided into an initial 12 weeks of intensive intervention during which participants are engaged on a weekly basis for group intervention followed by monthly follow-up sessions to help them maintain weight loss for long term. A recent study showed that participants in the Why WAIT program maintained $6.4 \%$ weight loss after 5 years, and participants who achieved $\geq$
$7 \%$ after the first year (53\%) maintained $9 \%$ weight loss after 5 years $[17 \bullet \bullet]$. Other studies on weight management programs in real-world clinical practice have also shown beneficial results over shorter durations [23-25]. The components of the Why WAIT program are described below and are summarized in Fig. 1.

\section{Components of Multidisciplinary Approach}

\section{Medication Adjustments}

Physicians, especially those working in primary care settings, are on the frontline in the fight against obesity and T2D. It is crucial for physicians to not only screen for obesity and diabetes but also to aggressively manage them early in the course of the disease. However, many studies reported that weight management is seldom discussed with patients due to lack of training, time, or reimbursement [26].

Meanwhile, many of the currently used antihyperglycemic medications are known to cause weight gain (e.g., insulins, sulfonylureas, glinides, thiazolidinediones) [12]. For optimal weight reduction through multidisciplinary approach, healthcare providers should reduce, substitute, or even stop, whenever possible, these medications at the beginning of the weight management program. They may be substituted, if applicable, by medications that are weight neutral or by those that enhance weight loss (e.g., metformin, DPP-4 inhibitors, $\alpha$-glucosidase inhibitors, GLP-1 analogs, SGLT-2 inhibitors, and pramlintide) (Table 1) [12]. Furthermore, use of FDA-
Fig. 1 The multidisciplinary approach to weight management in patients with type 2 diabetes and obesity

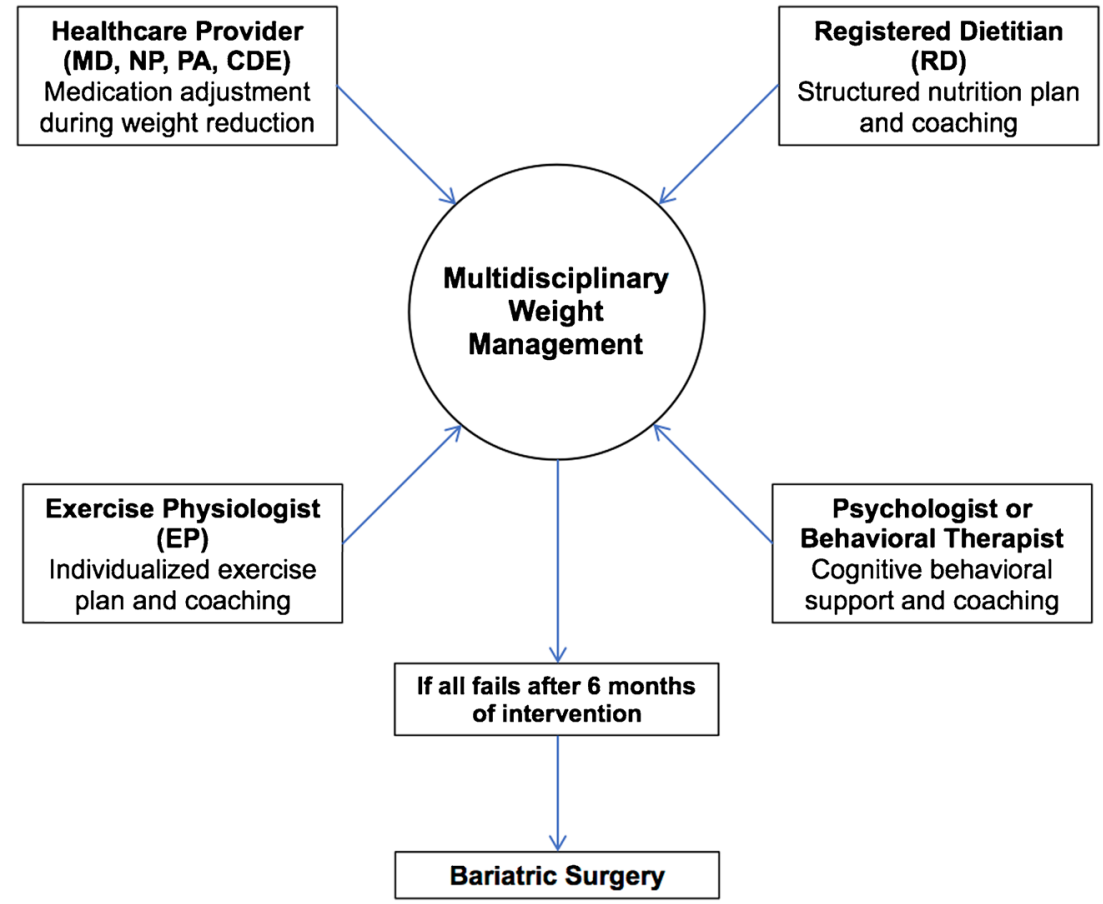


Table 1 Adjustment of diabetes medication during multidisciplinary weight management in patients with type 2 diabetes and obesity

\begin{tabular}{|c|c|c|c|c|}
\hline \multirow{3}{*}{ Effect on body weight } & \multirow{2}{*}{\multicolumn{2}{|c|}{$\frac{\text { List A }}{\text { Weight gain }}$}} & \multicolumn{2}{|l|}{ List B } \\
\hline & & & \multirow[t]{2}{*}{ Weight neutral } & \multirow[t]{2}{*}{ Weight loss } \\
\hline & Significant & Modest & & \\
\hline & Pioglitazone & $\begin{array}{l}\text { Sulfonylureas } \\
\text { Glimepiride } \\
\text { Glipizide XL }\end{array}$ & Metformin & $\begin{array}{l}\text { GLP-1 analogs } \\
\text { Exenatide } \\
\text { Exenatide ER } \\
\text { Liraglutide } \\
\text { Albiglutide } \\
\text { Dulaglutide } \\
\text { Semaglutide }\end{array}$ \\
\hline & $\begin{array}{c}\text { Sulfonylureas } \\
\text { Glyburide } \\
\text { Glipizide }\end{array}$ & $\begin{array}{l}\text { Glinides } \\
\text { Repaglinide } \\
\text { Nateglinide }\end{array}$ & $\begin{array}{l}\text { DPP-4 inhibitors } \\
\text { Sitagliptin } \\
\text { Saxaglipitin } \\
\text { Linagliptin } \\
\text { Alogliptin }\end{array}$ & \\
\hline & $\begin{array}{l}\text { Insulin } \\
\qquad \begin{array}{l}\text { NPH } \\
\text { Glargine } \\
\text { Regular }\end{array}\end{array}$ & $\begin{array}{l}\text { Insulin } \\
\text { Detemir } \\
\text { Degludec } \\
\text { Glargine U-300 }\end{array}$ & $\begin{array}{l}\alpha \text {-Glucosidase inhibitors } \\
\text { Acarbose } \\
\text { Miglitol }\end{array}$ & Pramlintide \\
\hline & $\begin{array}{l}\text { Aspart } \\
\text { Lispro } \\
\text { Glulisine }\end{array}$ & $\begin{array}{l}\text { Glulisine (PP) } \\
\text { Aspart (PP) }\end{array}$ & Colesevelam & $\begin{array}{c}\text { SGLT2-inhibitors } \\
\text { Canagliflozin } \\
\text { Dapagliflozin } \\
\text { Embagliflozin }\end{array}$ \\
\hline & & & Bromocriptine & \\
\hline Adjustments & Stop, reduce, $\mathrm{c}$ & switch & Continue & Add \\
\hline
\end{tabular}

$P P$ postprandial

approved anti-obesity medications (e.g., lorcaserin, naltrexone/bupropion, topiramate/phentermine, and liraglutide) is encouraged in certain patients with strong appetites [27]. Patients on insulin may be switched to long-acting insulins that induce less weight gain (e.g., insulin detemir, insulin degludec, and insulin glargine U-300) [28-31]. To avoid unnecessary food consumption, patients may be advised to administer short-acting insulin immediately after meals or within 20 min of starting the meal [32]. Two insulins are FDAapproved for postprandial injection: insulin glulisine and fast-acting insulin aspart [33, 34]. With this perspective, patients are educated on injecting insulin based on what was eaten rather than on what they had assumed would be eaten. This technique may reduce mealtime insulin doses and consequently lessen the weight-gaining effect of insulin [32].

Close monitoring of blood glucose levels is especially important during weight loss. Patients are advised to use a continuous glucose monitor or to check their blood glucose levels 5-8 times daily: before meals, before and after exercise, and at bed time. Blood glucose logs should be reviewed weekly during the intensive period of weight management by healthcare providers including physicians, nurse practitioners, physician assistants, or certified diabetes nurse-educators. Antihyperglycemic medications should be titrated accordingly to prevent hypoglycemia during weight reduction. Occurrence of hypoglycemia with weight loss as the result of improved insulin sensitivity can be a barrier to progressive weight loss and should be avoided even by primitive medication reductions if blood glucose is within target range.

\section{Nutrition Therapy}

Before insulin discovery, dietary intervention was the cornerstone of diabetes management. At that time, clinicians relied solely on carbohydrate restriction within a hypocaloric diet to manage hyperglycemia $[35,36]$. However, nutrition therapy was quickly sidelined after the introduction of insulin therapy in 1921. Over the last two decades, supervised nutrition therapy became one of the most effective methods of diabetes and weight management. We recently tested, in a randomized clinical trial, the effects of different models of nutrition therapy on A1C and body weight in patients with T2D and obesity [37]. Our study showed that a structured dietary plan delivered by a registered dietitian (RD) was superior to the currently 
recommended personalized dietary plan in improving glycemia and body weight [37]. Structured nutrition plans include menus, snack lists, and diabetes-specific formulas. Over 16 weeks of intervention, the use of a structured meal plan, either alone or in combination with weekly phone support by RD, resulted in reduction of $\mathrm{A} 1 \mathrm{C}$ by $-0.66 \%(95 \% \mathrm{CI}-1.03$ to -0.30$)$ and $-0.61 \%$ (95\% CI -1.0 to -0.23$)$, respectively. It also reduced body weight by $-3.49 \mathrm{~kg}(95 \% \mathrm{CI}-4.93$ to -2.05$)$ and $2.93 \mathrm{~kg}(95 \% \mathrm{CI}-4.45$ to -1.42$)$, respectively. In contrast, patients given an individualized meal plan did not show significant change in A1C or body weight from baseline [37].

Proper nutrition therapy usually starts by an RD evaluating potential participants. That evaluation includes review of dietary history and/or 24-h dietary recall and review of adherence to dietary recommendations during previous attempts of weight management. It also includes identification of potential barriers to following a nutrition plan. Each participant should receive a hypocaloric meal plan rounded to the nearest 1200,1500 , or $1800 \mathrm{kcal}$ level for ease of application based on their gender, height, and previous energy intake [22]. In the Look AHEAD study, participants whose weight was over $250 \mathrm{lbs}$. at baseline were put on a 1500-1800 cal diet plan, and those whose weight was less than 250 lbs. were put on a $1200-1500$ cal diet plan $[38,39]$. In Why WAIT, men are put on 1800 cal diet plans and women on $1500 \mathrm{cal}$ diet plans. If target weight loss is not achieved within 6 weeks, the dietary plan is advanced to 1500 and $1200 \mathrm{cal}$, respectively. Women who are shorter than $150 \mathrm{~cm}$ are put on $1200 \mathrm{cal}$ diet plans from the beginning of the program. Structured meal plans provide approximately $40-45 \%$ of daily energy intake from carbohydrates with $14 \mathrm{~g}$ of fiber per $1000 \mathrm{cal},<35 \%$ from fat with $<10 \%$ from saturated fat, and $1-1.5 \mathrm{~g} / \mathrm{kg}$ of adjusted body weight from protein [40, 41]. Effective dietary plans do not calculate protein intake as a percentage of the total calories consumed to avoid unintended reduction in absolute protein intake in a hypocaloric diet. Reduction in absolute protein intake may accelerate lean muscle loss during weight reduction [42]. Minimizing the loss of lean muscle mass during weight management is essential for long-term maintenance of weight loss.

Use of diabetes-specific formulas (DSF) for meal or calorie replacements have been shown to be associated with improved glycemic control and weight reduction [43-46]. Several meal replacement formulas have been tested for weight management [47]. We previously showed that patients with T2D who consumed DSF for breakfast had a lower glucose excursion compared to oatmeal with the same calorie content [48]. Several DSFs were used in both the Look AHEAD study and the Why WAIT program for the initial 6-20 weeks to enhance initial weight reduction [39]. Participants may choose to continue to consume DSFs or to replace them with natural foods after the program.
Participants should also be provided with a list of snack options of 100-200 cal and advised to consume two of them between meals. Their caloric content should be calculated within the prescribed total daily calories. In structured nutrition plans, patients are provided with menus for dinner with details about their ingredients, cooking instructions, and nutrition facts. Participants find it easier to choose a dinner entrée from specified menus rather than calculating calories or following general instructions. Each patient should be provided with a food log, which is reviewed weekly by an RD during the intensive phase of intervention to ensure adherence to the prescribed dietary plan.

\section{Exercise Intervention}

For better long-term results, an exercise physiologist (EP) develops a personalized exercise plan for each patient based on the individual's age, gender, health status, and exercise capacity. In clinical practice, exercise capacity may be tested by a simple method such as the 6-min walk test [49]. The typical $150 \mathrm{~min} /$ week of aerobic exercise or 10,000 steps per day improves fitness but it is not enough for weight reduction or for maintenance of weight loss [50]. Effective exercise intervention for weight management should include a balanced mix of aerobic (endurance) exercise to promote cardiovascular health, resistance (strength) exercise to maintain muscle mass, and flexibility (stretch) exercise to enhance functional capabilities and reduce risk of injury. Exercise plans may progress gradually over $12-24$ weeks from $20 \mathrm{~min} /$ day for 4 days/week to $60 \mathrm{~min} /$ day for 5-6 days/week. After completing the initial intensive phase, participants are usually encouraged to continue to exercise for $60 \mathrm{~min} / \mathrm{day}, 5$ 6 days/week and maintain $\geq 300$ min per week with an emphasis on resistance training to maintain muscle mass. Resistance training is especially important since diabetes is known to worsen sarcopenia (muscle loss that frequently occurs with aging) [51]. Short bouts of exercise of 10 min each distributed during the day were shown to be more sustainable and were associated with similar benefits seen with longer exercise sessions [52]. Use of different exercise methods like circuit and interval training reduce boredom and increase duration of exercises [52, 53]. Exercise is particularly important after the intensive phase of weight management as it helps maintain the weight loss achieved during the intensive period [50].

\section{Cognitive Behavioral Support}

The ability to maintain long-term dietary and exercise modifications relies heavily on patients' mental and motivational status, which should be addressed through cognitivebehavioral therapy (CBS). Clinical psychologists, behavioral 
therapists, or social workers are ideal coaches in leading behavioral support sessions, which can be individual or within group settings. Sessions incorporate typical components of CBS, which include behavioral goal setting, self-monitoring of eating and exercise, stimulus control techniques, cognitive restructuring, assertive communication skills, and prevention of relapse $[15,54]$. This model was used in the DPP, Look AHEAD study, and Why WAIT program, where it was described in detail $[39,55]$.

\section{Use of Digital Health for Scalable Application of Lifestyle Intervention in Patients with Diabetes}

Because of the comprehensive nature of the multidisciplinary approach to weight management, access to such programs may be limited to few patients due to cost or lack of specialized healthcare providers. Mobile phone applications can deliver a diabetes-specific multidisciplinary weight management program at lower cost and with greater accessibility to patients. Currently, over 28,000 smartphone applications focusing on weight management through diet and exercise tracking exist [56], many of which have already demonstrated their capacity to improve body weight and health outcomes in people with diabetes [57, 58]. However, mobile phone applications on the market include, on average, less than $19 \%$ of behavioral strategies used in evidence-based lifestyle intervention programs [59]. In particular, strategies for educating patients during their weight management, providing motivational support, reducing stress, and assisting patients with health decision-making have been overlooked [59]. With the introduction of evidence-based design and the integration of blood glucose monitoring systems, mobile health applications present an opportunity for improved accessibility and scalability of weight management interventions.

\section{Bariatric Surgery}

Bariatric surgery is increasingly used for obesity management in patients with diabetes [60]. It should be considered as a valid option for patients with T2D and class 2 and 3 obesity who are unable to reduce their body weight after 6 months of intensive lifestyle intervention. Bariatric surgery, especially Roux-en-Y gastric bypass (RYGB), is a drastic procedure but frequently results in long-term weight loss [61-63]. Studies have shown that among patients with T2D, bariatric surgery improves glycemic control and reduces requirements of antihyperglycemic medications [61-63]. Bariatric surgery may induce partial or complete remission from T2D for several years [64]. The recent and more popular sleeve gastrectomy procedure carries fewer complications than RYGB surgery [65]. A recent study demonstrated a synergistic effect of completing a multidisciplinary weight management program before receiving RYGB compared to receiving RYGB alone [66••]. Serious side events like severe hypoglycemia and severe postural hypotension are not uncommon after RYGB and may require revision of the surgery [67]. A similar procedure called endoscopic sleeve gastroplasty can be done through a gastric endoscopy, eliminating the need for laparoscopic approach [68]. The least effective bariatric surgery for long-term results in patients with T2D is laparoscopic adjustable gastric banding (LAGB) [69]. Over the last few years, US bariatric surgeons started to prefer sleeve gastrectomy over other types of bariatric surgery for its better results and limited complications $[65,70]$. Comparison between intensive medical and surgical interventions favored surgery for the magnitude of weight reduction, but the overall quality-of-life measures improved more significantly with non-surgical intervention [71]. Changes in A1C were similar after 1 year between the Why WAIT method of nonsurgical intervention and LAGB [71].

\section{Conclusion}

Type 2 diabetes is strongly associated with being overweight or obese. The causes behind both conditions are multifaceted, hence the importance of a multidisciplinary approach to weight management to control both conditions. Recently, a multidisciplinary weight management program was shown to result in long-term weight reduction for 5 years in realworld clinical practice. Intervention methods can be conducted digitally for scalable application to the broader population of patients with T2D and obesity.

\section{Compliance with Ethical Standards}

Conflict of Interest Adham Mottalib and Sahar Ashrafzadeh declare that they have no conflicts of interest. Osama Hamdy is on the advisory board of Astra Zeneca, Inc., is consultant to Merck, Inc. and Sanofi-Aventis, Inc., and is a shareholder of Healthimation, Inc. He receives research grants from Novo Nordisk, Inc. and the National Dairy Council.

Human and Animal Rights and Informed Consent All reported studies/ experiments with human or animal subjects performed by the authors have been previously published and complied with all applicable ethical standards (including the Helsinki declaration and its amendments, institutional/national research committee standards, and international/national/institutional guidelines).

Open Access This article is distributed under the terms of the Creative Commons Attribution 4.0 International License (http:// creativecommons.org/licenses/by/4.0/), which permits unrestricted use, distribution, and reproduction in any medium, provided you give appropriate credit to the original author(s) and the source, provide a link to the Creative Commons license, and indicate if changes were made. 


\section{References}

Papers of particular interest, published recently, have been highlighted as:

- Of importance

-• Of major importance

1. Caballero B. The global epidemic of obesity: an overview. Epidemiol Rev. 2007;29(1):1-5.

2. Herman WH, Zimmet P. Type 2 diabetes: an epidemic requiring global attention and urgent action. Diabetes Care. 2012;35(5):9434. https://doi.org/10.2337/dc12-0298.

3. Prevention CfDCa. Prevalence of overweight and obesity among adults with diagnosed diabetes-United States, 1988-1994 and 1999-2002. MMWR Morb Mortal Wkly Rep. 2004;53(45):10668.

4. Daousi C, Casson IF, Gill GV, MacFarlane IA, Wilding JP, Pinkney $\mathrm{JH}$. Prevalence of obesity in type 2 diabetes in secondary care: association with cardiovascular risk factors. Postgrad Med J. 2006;82(966):280-4. https://doi.org/10.1136/pmj.2005.039032.

5. Bhupathiraju SN, Hu FB. Epidemiology of obesity and diabetes and their cardiovascular complications. Circ Res. 2016;118(11): 1723-35. https://doi.org/10.1161/circresaha.115.306825. This study describes trends in the current obesity and diabetes epidemics in the USA and their associated health complications.

6. Holmes MV, Pulit SL, Lindgren CM. Genetic and epigenetic studies of adiposity and cardiometabolic disease. Genome Med. 2017;9(1):82. https://doi.org/10.1186/s13073-017-0474-5.

7. ADA. Lifestyle management. Sec. 4. In Standards of Medical Care in Diabetes-2017. Diabetes Care. 2017;40(Supplement 1):S3343. https://doi.org/10.2337/dc17-S007.

8. Garber AJ, Abrahamson MJ, Barzilay JI, Blonde L, Bloomgarden ZT, Bush MA, et al. Consensus statement by the American Association of Clinical Endocrinologists and American College of Endocrinology on the comprehensive type 2 diabetes management algorithm-2018 executive summary. Endocr Pract. 2018;24(1): 91-120. https://doi.org/10.4158/cs-2017-0153.

9. Chin MH, Cook S, Jin L, Drum ML, Harrison JF, Koppert J, et al. Barriers to providing diabetes care in Community Health Centers. Diabetes Care. 2001;24(2):268-74. https://doi.org/10.2337/diacare. 24.2.268.

10. Wens J, Vermeire E, Royen PV, Sabbe B, Denekens JGP. 'Perspectives of type 2 diabetes patients' adherence to treatment: a qualitative analysis of barriers and solutions. BMC Fam Pract. 2005;6(1):20. https://doi.org/10.1186/1471-2296-6-20.

11. Jansink R, Braspenning J, van der Weijden T, Elwyn G, Grol R. Primary care nurses struggle with lifestyle counseling in diabetes care: a qualitative analysis. BMC Fam Pract. 2010;11(1):41. https:// doi.org/10.1186/1471-2296-11-41.

12. Mitri J, Hamdy O. Diabetes medications and body weight. Expert Opin Drug Saf. 2009;8(5):573-84. https://doi.org/10.1517/ 14740330903081725.

13. Kahn SE, Hull RL, Utzschneider KM. Mechanisms linking obesity to insulin resistance and type 2 diabetes. Nature. 2006;444(7121): 840-6. https://doi.org/10.1038/nature05482.

14. Hamdy O, Ledbury S, Mullooly C, Jarema C, Porter S, Ovalle K, et al. Lifestyle modification improves endothelial function in obese subjects with the insulin resistance syndrome. Diabetes Care. 2003;26(7):2119-25.

15. Knowler WC, Barrett-Connor E, Fowler SE, Hamman RF, Lachin JM, Walker EA, et al. Reduction in the incidence of type 2 diabetes with lifestyle intervention or metformin. N Engl J Med. 2002;346(6):393-403. https://doi.org/10.1056/NEJMoa012512.
16. Wing RR, Bolin P, Brancati FL, Bray GA, Clark JM, Coday M, et al. Cardiovascular effects of intensive lifestyle intervention in type 2 diabetes. N Engl J Med. 2013;369(2):145-54. https://doi.org/10. 1056/NEJMoa1212914.

17.• Hamdy O, Mottalib A, Morsi A, El-Sayed N, Goebel-Fabbri A, Arathuzik G, et al. Long-term effect of intensive lifestyle intervention on cardiovascular risk factors in patients with diabetes in realworld clinical practice: a 5-year longitudinal study. BMJ Open Diabetes Res Care. 2017;5(1):e000259. This study reported that long-term weight loss can be achieved by patients with diabetes and obesity through a lifestyle intervention program in realworld clinical practice.

18. Yumuk V, Fruhbeck G, Oppert JM, Woodward E, Toplak H. An EASO position statement on multidisciplinary obesity management in adults. Obesity facts. 2014;7(2):96-101. https://doi.org/10.1159/ 000362191.

19. Phelan S, Wyatt HR, Hill JO, Wing RR. Are the eating and exercise habits of successful weight losers changing? Obesity (Silver Spring, Md). 2006;14(4):710-6. https://doi.org/10.1038/oby.2006.81.

20. Thomas JG, Bond DS, Phelan S, Hill JO, Wing RR. Weight-loss maintenance for 10 years in the National Weight Control Registry. Am J Prev Med. 2014;46(1):17-23. https://doi.org/10.1016/j. amepre.2013.08.019.

21. Montesi L, El Ghoch M, Brodosi L, Calugi S, Marchesini G, Dalle Grave R. Long-term weight loss maintenance for obesity: a multidisciplinary approach. Diabetes, metabolic syndrome and obesity : targets and therapy 2016;9:37-46. doi:https://doi.org/10.2147/ dmso.s89836.

22. Hamdy O, Carver C. The Why WAIT program: improving clinical outcomes through weight management in type 2 diabetes. Curr Diabetes Rep. 2008;8(5):413-20.

23. Jennings A, Hughes CA, Kumaravel B, Bachmann MO, Steel N, Capehorn M, et al. Evaluation of a multidisciplinary Tier 3 weight management service for adults with morbid obesity, or obesity and comorbidities, based in primary care. Clinical obesity. 2014;4(5): 254-66. https://doi.org/10.1111/cob.12066.

24. Lih A, Pereira L, Bishay RH, Zang J, Omari A, Atlantis E, et al. A novel multidisciplinary intervention for long-term weight loss and glycaemic control in obese patients with diabetes. J Diabetes Res. 2015;2015:729567. https://doi.org/10.1155/2015/729567.

25. Romanova M, Liang LJ, Deng ML, Li Z, Heber D. Effectiveness of the MOVE! Multidisciplinary weight loss program for veterans in Los Angeles. Prev Chron Dis. 2013;10:E112. https://doi.org/10. 5888/pcd10.120325.

26. Mauro M, Taylor V, Wharton S, Sharma AM. Barriers to obesity treatment. Eur J Int Med. 2008;19(3):173-80. https://doi.org/10. 1016/j.ejim.2007.09.011.

27. Mordes JP, Liu C, Xu S. Medications for weight loss. Current opinion in endocrinology, diabetes, and obesity 2015;22(2):91-7. doi: https://doi.org/10.1097/med.0000000000000140.

28. Yki-Jarvinen H, Kauppila M, Kujansuu E, Lahti J, Marjanen $\mathrm{T}$, Niskanen L, et al. Comparison of insulin regimens in patients with non-insulin-dependent diabetes mellitus. N Engl J Med. 1992;327(20):1426-33. https://doi.org/10.1056/ nejm199211123272005.

29. Heller S, Buse J, Fisher M, Garg S, Marre M, Merker L, et al. Insulin degludec, an ultra-longacting basal insulin, versus insulin glargine in basal-bolus treatment with mealtime insulin aspart in type 1 diabetes (BEGIN Basal-Bolus Type 1): a phase 3, randomised, open-label, treat-to-target non-inferiority trial. Lancet (London, England). 2012;379(9825):1489-97. https://doi.org/10. 1016/s0140-6736(12)60204-9.

30. Mathieu C, Hollander P, Miranda-Palma B, Cooper J, Franek E, Russell-Jones D, et al. Efficacy and safety of insulin degludec in a flexible dosing regimen vs insulin glargine in patients with type 1 diabetes (BEGIN: Flex T1): a 26-week randomized, treat-to-target 
trial with a 26-week extension. J Clin Endocrinol Metab. 2013;98(3):1154-62. https://doi.org/10.1210/jc.2012-3249.

31. Home PD, Bergenstal RM, Bolli GB, Ziemen M, Rojeski M, Espinasse $\mathrm{M}$, et al. New insulin glargine 300 units $/ \mathrm{mL}$ versus glargine 100 units $/ \mathrm{mL}$ in people with type 1 diabetes: a randomized, phase 3a, open-label clinical trial (EDITION 4). Diabetes Care. 2015;38(12):2217-25. https://doi.org/10.2337/dc15-0249.

32. Garg SK, Rosenstock J, Ways K. Optimized basal-bolus insulin regimens in type 1 diabetes: insulin glulisine versus regular human insulin in combination with basal insulin glargine. Endocr Pract. 2005;11(1):11-7. https://doi.org/10.4158/ep.11.1.11.

33. Food and Drug Administration. FIASP $®$ (insulin aspart injection) [label]. Novo Nordisk A/S, Bagsvaerd, Denmark. 2017.

34. Food and Drug Administration. APIDRA ${ }^{\circledR}$ (insulin glulisine [rDNA origin] injection) [label]. Sanofi-Aventis U.S. LLC, Bridgewater, NJ. 2015.

35. Joslin EP. The treatment of diabetes mellitus. Can Med Assoc J. 1916;6(8):673-84.

36. Allen FM, Stillman E, Fitz R. Total dietary regulation in the treatment of diabetes. vol 11. Rockefeller Institute for Medical Research; 1919.

37. Mottalib A, Salsberg V, Mohd-Yusof B-N, Mohamed W, Carolan P, Pober DM, et al. Effects of nutrition therapy on $\mathrm{HbA} 1 \mathrm{c}$ and cardiovascular disease risk factors in overweight and obese patients with type 2 diabetes. Nutr J. 2018;17(1):42. https://doi.org/10.1186/ s12937-018-0351-0.

38. Eight-year weight losses with an intensive lifestyle intervention: The Look AHEAD Research Group. Obesity (Silver Spring, Md). 2014;22(1):5-13. doi:https://doi.org/10.1002/oby.20662

39. Wadden TA, West DS, Delahanty L, Jakicic J, Rejeski J, Williamson D, et al. The Look AHEAD study: a description of the lifestyle intervention and the evidence supporting it. Obesity (Silver Spring, Md). 2006;14(5):737-52. https://doi.org/10.1038/ oby.2006.84.

40. Giusti J, Rizzotto JA. Interpreting the Joslin Diabetes Center and Joslin Clinic Clinical Nutrition Guideline for overweight and obese adults with type 2 diabetes. Curr Diabetes Rep. 2006;6(5):405-8.

41. Campbell A. Tackling "diabesity" head-on. Joslin Diabetes Center's new nutrition guideline. Diabetes self-management 2005;22(6):40, 2-4.

42. Hamdy O, Horton ES. Protein content in diabetes nutrition plan. Curr Diabetes Rep. 2011;11(2):111-9. https://doi.org/10.1007/ s11892-010-0171-x.

43. Wadden TA, Neiberg RH, Wing RR, Clark JM, Delahanty LM, Hill JO, Krakoff J, Otto A, Ryan DH, Vitolins MZ, Look AHEAD Research Group Four-year weight losses in the look AHEAD study: factors associated with long-term success. Obesity (Silver Spring, Md). 2011;19(10):1987-1998. doi:https://doi.org/10.1038/oby. 2011.230.

44. Cheskin LJ, Mitchell AM, Jhaveri AD, Mitola AH, Davis LM, Lewis RA, et al. Efficacy of meal replacements versus a standard food-based diet for weight loss in type 2 diabetes: a controlled clinical trial. Diabetes Educ. 2008;34(1):118-27. https://doi.org/ $10.1177 / 0145721707312463$.

45. Heymsfield S, Van Mierlo C, Van der Knaap H, Heo M, Frier H. Weight management using a meal replacement strategy: meta and pooling analysis from six studies. Int J Obes. 2003;27(5):537-49.

46. Li D, Zhang P, Guo H, Ling W. Taking a low glycemic index multinutrient supplement as breakfast improves glycemic control in patients with type 2 diabetes mellitus: a randomized controlled trial. Nutrients. 2014;6(12):5740-55. https://doi.org/10.3390/ nu6125740.

47. Hamdy O, Zwiefelhofer D. Weight management using a meal replacement strategy in type 2 diabetes. Curr Diabetes Rep. 2010;10(2):159-64. https://doi.org/10.1007/s11892-010-0103-9.
48. Mottalib A, Mohd-Yusof BN, Shehabeldin M, Pober DM, Mitri J, Hamdy O. Impact of diabetes-specific nutritional formulas versus oatmeal on postprandial glucose, insulin, GLP-1 and postprandial Lipidemia. Nutrients. 2016;8(7):443. https://doi.org/10.3390/ nu8070443.

49. Capodaglio P, De Souza SA, Parisio C, Precilios H, Vismara L, Cimolin V, et al. Reference values for the 6-min walking test in obese subjects. Disabil Rehabil. 2013;35(14):1199-203. https:// doi.org/10.3109/09638288.2012.726313.

50. Swift DL, Johannsen NM, Lavie CJ, Earnest CP, Church TS. The role of exercise and physical activity in weight loss and maintenance. Prog Cardiovasc Dis. 2014;56(4):441-7. https://doi.org/10. 1016/j.pcad.2013.09.012.

51. Umegaki H. Sarcopenia and diabetes: hyperglycemia is a risk factor for age-associated muscle mass and functional reduction. J Diabetes Investig. 2015;6(6):623-4. https://doi.org/10.1111/jdi.12365.

52. Jefferis BJ, Parsons TJ, Sartini C, Ash S, Lennon LT, Wannamethee SG, et al. Does duration of physical activity bouts matter for adiposity and metabolic syndrome? A cross-sectional study of older British men. Int J Behav Nutr Phys Act. 2016;13(36):36. https://doi. org/10.1186/s12966-016-0361-2.

53. Glazer NL, Lyass A, Esliger DW, Blease SJ, Freedson PS, Massaro $\mathrm{JM}$, et al. Sustained and shorter bouts of physical activity are related to cardiovascular health. Med Sci Sports Exerc. 2013;45(1):109 15. https://doi.org/10.1249/MSS.0b013e31826beae5.

54. Wadden TA, Stunkard AJ. Handbook of obesity treatment: Guilford Press; 2002.

55. The Look AHEAD Research Group: description of lifestyle intervention. Diabetes Care. 2002;25(12):2165-71.

56. Nikolaou CK, Lean MEJ. Mobile applications for obesity and weight management: current market characteristics. Int J Obes. 2016;41(1):200-2. https://doi.org/10.1038/ijo.2016.186.

57. Bonn SE, Alexandrou C, Steiner KH, Wiklander K, Östenson C, Löf $\mathrm{M}$, et al. App-technology to increase physical activity among patients with diabetes type 2-the DiaCert-study, a randomized controlled trial. BMC Public Health. 2018;18(1):119. https://doi. org/10.1186/s12889-018-5026-4.

58. Carter MC, Burley VJ, Nykjaer C, Cade JE. Adherence to a smartphone application for weight loss compared to website and paper diary: pilot randomized controlled trial. J Med Internet Res. 2013;15(4):e32. https://doi.org/10.2196/jmir.2283.

59. Pagoto S, Schneider K, Jojic M, DeBiasse M, Mann D. Evidencebased strategies in weight-loss mobile apps. Am J Prev Med. 2013;45(5):576-82. https://doi.org/10.1016/j.amepre.2013.04.025.

60. El Khoury L, Chouillard E, Chahine E, Saikaly E, Debs T, Kassir R. Metabolic surgery and diabesity: a systematic review. Obes Surg. 2018;28:2069-77. https://doi.org/10.1007/s11695-018-3252-6.

61. Schauer PR, Bhatt DL, Kirwan JP, Wolski K, Aminian A, Brethauer $\mathrm{SA}$, et al. Bariatric surgery versus intensive medical therapy for diabetes - 5-year outcomes. N Engl J Med. 2017;376(7):641-51.

62. Ikramuddin S, Billington CJ, Lee W-J, Bantle JP, Thomas AJ, Connett JE, et al. Roux-en-Y gastric bypass for diabetes (the Diabetes Surgery Study): 2-year outcomes of a 5-year, randomised, controlled trial. Lancet Diabetes Endocrinol. 2015;3(6):413-22.

63. Sjöström L. Review of the key results from the Swedish Obese Subjects (SOS) trial-a prospective controlled intervention study of bariatric surgery. J Intern Med. 2013;273(3):219-34.

64. Yska JP, van Roon EN, de Boer A, Leufkens HG, Wilffert B, de Heide LJ, et al. Remission of type 2 diabetes mellitus in patients after different types of bariatric surgery: a population-based cohort study in the United Kingdom. JAMA Surgery. 2015;150(12):112633. https://doi.org/10.1001/jamasurg.2015.2398.

65. Peterli R, Borbely Y, Kern B, Gass M, Peters T, Thurnheer M, et al. Early results of the Swiss Multicentre Bypass or Sleeve Study (SMBOSS): a prospective randomized trial comparing laparoscopic sleeve gastrectomy and Roux-en-Y gastric bypass. Ann Surg. 
2013;258(5):690-4; discussion 5. https://doi.org/10.1097/SLA. 0b013e3182a67426.

66.• Patel P, Hartland A, Hollis A, Ali R, Elshaw A, Jain S, et al. Tier 3 multidisciplinary medical weight management improves outcome of Roux-en-Y gastric bypass surgery. Ann R Coll Surg Engl. 2015;97(3): 235-7. https://doi.org/10.1308/003588414x14055925061838. This study demonstrates the benefits of a weight management program prior to gastric bypass surgery in improving weight loss outcomes in patients.

67. Goldfine AB, Patti ME. How common is hypoglycemia after gastric bypass? Obesity (Silver Spring, Md). 2016;24(6):1210-1. https://doi.org/10.1002/oby.21520.

68. Abu Dayyeh BK, Rajan E, Gostout CJ. Endoscopic sleeve gastroplasty: a potential endoscopic alternative to surgical sleeve gastrectomy for treatment of obesity. Gastrointest Endosc. 2013;78(3):530-5. https://doi.org/10.1016/j.gie.2013.04.197.
69. Franco JV, Ruiz PA, Palermo M, Gagner M. A review of studies comparing three laparoscopic procedures in bariatric surgery: sleeve gastrectomy, Roux-en-Y gastric bypass and adjustable gastric banding. Obes Surg. 2011;21(9):1458-68. https://doi.org/10. 1007/s11695-011-0390-5.

70. Cho JM, Kim HJ, Lo Menzo E, Park S, Szomstein S, Rosenthal RJ. Effect of sleeve gastrectomy on type 2 diabetes as an alternative treatment modality to Roux-en-Y gastric bypass: systemic review and meta-analysis. Surg Obes Relat Dis. 2015;11(6):1273-80. https://doi.org/10.1016/j.soard.2015.03.001.

71. Ding SA, Simonson DC, Wewalka M, Halperin F, Foster K, Goebel-Fabbri A, et al. Adjustable gastric band surgery or medical management in patients with type 2 diabetes: a randomized clinical trial. J Clin Endocrinol Metab. 2015;100(7):2546-56. https://doi. org/10.1210/jc.2015-1443. 